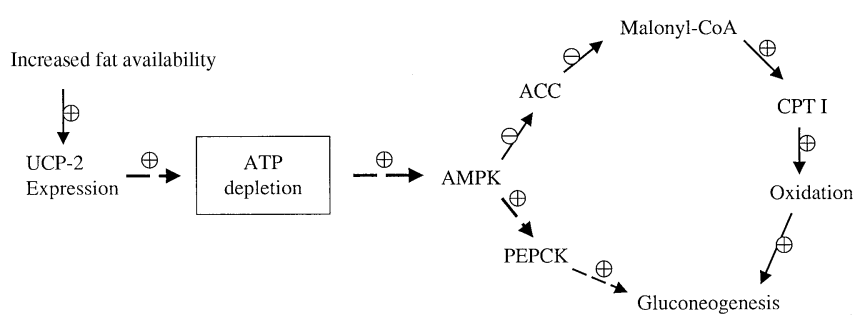

Fig. 1. The emerged significance of $U C P-2$ expression in the liver. The solid line is the pathway that has been established, whereas the dashed line is the pathway that needs further confirmation. $\ominus$ represents enhancement, $\oplus$ represents inhibition. ATP depletion serves as the link between UCP-2 activity and AMPK signalling system. The overall scheme suggests a metabolic flux from increased fat availability to enhanced gluconeogenesis (as illustrated by the dashed line)

generation only. When the body is facing a high-fat challenge such as in obesity or high-fat feeding, the expression of $U C P-2$ could serve as a means to discharge fat-associated energy by not only enhancing proton leak but also transforming fuel configuration which is achieved by stimulating gluconeogenesis. As such, a loop between fat and glucose metabolism is formed (Fig. 1). To further elucidate the 'bona fide' role of UCP-2 in hepatocytes, a tissue-specific knockout strategy rather than global null-mouse model is suggested since transgenic studies have shown that phenotypes resulting from global knockout model tends to be confounded by in vivo compensation mechanism whereas tissue specific disruption of the UCP-2 gene could reveal its natural attribute.

\section{S. Song}

Department of Pharmacology, College of Physicians and Surgeons, Columbia University, 630 West 168th Street, New York, NY 10032, USA

\section{References}

1. Saleh MC, Wheeler MB, Chan CB (2002) Uncoupling protein-2: evidence for its function as a metabolic regulator. Diabetologia 45:174-187

2. Baffy G, Zhang CY, Glickman JN, Lowell BB (2002) Obesity-related fatty liver is unchanged in mice deficient for mitochondrial uncoupling protein 2. Hepatology 35:753761

3. Hanson RW, Reshef L (1997) Regulation of phosphoenolpyruvate carboxykinase (GTP) gene expression. Annu Rev Biochem 66:581-611

4. Chavin KD, Yang S, Lin HZ et al. (1999) Obesity induces expression of uncoupling protein-2 in hepatocytes and promotes liver ATP depletion. J Biol Chem 274:56925700

5. Hardie DG, Hawley SA (2001) AMP-activated protein kinase: the energy charge hypothesis revisited. Bioessays 23:1112-1119

6. Hubert A, Husson A, Chedeville A, Lavoinne A (2000) AMP-activated protein kinase counteracted the inhibitory effect of glucose on the phosphoenolpyruvate carboxykinase gene expression in rat hepatocytes. FEBS Lett 481:209212

7. Miller JC, Colagiuri S (1994) The carnivore connection: dietary carbohydrate in the evolution of NIDDM. Diabetologia 37:1280-1286
8. Tu N, Chen H, Winnikes U, et al. (1999) Molecular cloning and functional characterization of the promoter region of the human uncoupling protein-2 gene. Biochem Biophys Res Commun 265:326-334

Corresponding author: S. Song, Department of Pharmacology, College of Physicians and Surgeons, Columbia University, 630 West 168th Street, New York, NY 10032, USA, E-mail: ss1768@columbia.edu

\section{Authors' reply}

To the Editor: It is an author's reward when one's published findings, opinions or speculations generate debate, corroboration and/or enthusiasm within a field. Indeed, there have been some new and intriguing findings regarding the potential role of uncoupling protein- 2 in the liver since our manuscript was submitted for publication. Initial studies showed a noticeable lack of uncoupling protein-2 in normal rat hepatocytes except under certain metabolic conditions. Instead, ucp 2 gene expression in the liver appeared to be limited to non-parenchymal cells with a noticeable predominance in Kupffer cells [1]. More recently, demonstrable levels of ucp 2 mRNA have been described in cultured rat hepatocytes [2]. Moreover, the authors demonstrated a more profound up-regulation of ucp2 gene expression in rat hepatocytes by polyunsaturated fatty acids with both monounsaturated and saturated fatty acids eliciting more modest increases in ucp 2 mRNA levels [2]. In addition, it is proposed that the up-regulation of ucp 2 gene expression in response to polyunsaturated fatty acids could be mediated through a prostaglandin signalling pathway in which peroxisome proliferator-activated receptor- $\alpha$ could be activated. While the evidence supporting the proposed regulation of $u c p 2$ gene expression by peroxisome proliferator-activated receptor$\alpha$ is convincing, there remains some uncertainty as to the significance of this effect in the liver. A recent finding by Nakatani et al. [3] indicates that activation of peroxisome proliferator-activated receptor- $\alpha$ increases $u c p 2$ gene transcription rather than enhancing $u c p 2$ mRNA stability in rodent hepatocytes. Those authors suggest that $u c p 2$ gene expression might not be as responsive to reactive oxygen species production as was first thought.

Very little is known about the possible contribution of uncoupling protein-2 to fuel metabolism in liver cells. Given that the liver plays an integral role in nutrient partitioning and is central to several pathways including lipolysis, lipogenesis, glycolysis and gluconeogenesis, and in light of a proposed role for uncoupling protein-2 in lipid and glucose metabolism in other tissues, it is conceivable that uncoupling protein-2 in hepatocytes could contribute to metabolic homeostasis. We find the proposed connection between uncoupling protein-2-induced ATP depletion and 5'-AMP-activated protein kinase activation, and yet further, gluconeogenesis within hepatocytes, to be thought-provoking and insightful. If such a pathway does exist, it is likely to be operative only under specific metabolic conditions. In $o b / o b$ mice, a model for non-alcoholic fatty liver

DOI 10.1007/s00125-002-0973-8

Received: 6 August 2002

Published online: 23 November 2002

(C) Springer-Verlag 2002 
disease in which increased uncoupling protein-2 has been documented $[4,5]$, phosphoenolpyruvate carboxykinase is found to be reduced [6], seemingly ruling out a straight-forward relation between uncoupling protein-2 and gluconeogenesis even in a mildly diabetic animal such as the obese mouse. As the author, himself, acknowledges it has yet to be proven that the proposed cascade of events does in fact occur and we await with much interest the findings of those studies.

M. C. Saleh ${ }^{1}$, M. B. Wheeler ${ }^{2}$, C. B. Chan ${ }^{1}$

${ }^{1}$ Department of Anatomy and Physiology, University of Prince Edward Island, Charlottetown, PE, Canada C1A 4P3

2 Departments of Medicine and Physiology, University of Toronto, Toronto, Canada

\section{References}

1. Larrouy D, Laharrague P, Carrera G et al. (1997) Kupffer cells are a dominant site of uncoupling protein 2 expression in rat liver. Biochem Biophys Res Commun 235: 760-764
2. Armstrong MB, Towle HC (2001) Polyunsaturated fatty acids stimulate hepatic UCP-2 expression via a PPAR $\alpha$ mediated pathway. Am J Physiol Endocrinol Metab 281: E1197-E1204

3. Nakatani T, Tsuboyama-Kasaoka N, Takahashi M, Miura S, Ezaki O (2002) Mechanism for peroxisome proliferator-activated receptor- $\alpha$ activator-induced up-regulation of UCP2 mRNA in rodent hepatocytes. J Biol Chem 277: 9562-9569

4. Yang SQ, Zhu H, Li Y et al. (2000) Mitochondrial adaptations to obesity-related oxidant stress. Arch Biochem Biophys 378: 259-268

5. Rashid A, Wu T-C, Huang C-C et al. (1999) Mitochondrial proteins that regulate apoptosis and necrosis are induced in mouse fatty liver. Hepatology 29: 1131-1138

6. Yang SQ, Lin HZ, Mandal AK, Huang J, Diehl AM (2001) Disrupted signaling and inhibited regeneration in obese mice with fatty livers: implications for nonalcoholic fatty liver disease pathophysiology. Hepatology 34: 694-706

Corresponding author: C. B. Chan, Department of Anatomy and Physiology, University of Prince Edward Island, Charlottetown, PE, Canada C1A 4P3, E-mail: cchan@upei.ca, Tel.: +1-902-5660814, Fax: +1-902-5660832

\section{Observations}

\section{Circulating ghrelin concentrations are reduced in healthy offspring of Type 2 diabetic subjects, and are increased in women independent of a family history of Type 2 diabetes}

To the Editor: Ghrelin is a new 28 amino acid acylated peptide hormone [1] identified as the endogenous ligand for the growth hormone secretagogue receptor. In both animals and humans ghrelin stimulates food intake $[1,2]$ and is reversibly influenced by energy status, decreased in obesity [3] and increased in food deprived conditions [4]. These findings, together with potential effects on glucose homeostasis, makes ghrelin a potentially important player in the pathophysiology of Type 2 diabetes.

Healthy offspring of Type 2 diabetic patients have often been considered a model of studying the early metabolic aberrations in the development of Type 2 diabetes. We sought to determine the involvement of ghrelin in the possible development of Type 2 diabetes by comparing fasting circulating concentrations of ghrelin in 23 healthy but insulin resistant first degree relatives of Type 2 diabetic patients, and 16 healthy control subjects matched by age, sex, and BMI. All gave written consent to participate and the study was approved by the local ethics committee of the county of Aarhus and conducted in accordance with the guidelines proposed in the Declaration of Helsinki.

All subjects were examined by measuring anthropometric variables, body-composition, fasting samples of plasma ghrelin,

DOI 10.1007/s00125-002-0985-4

Received: 21 May 2002 / Accepted: 13 August 2002

Published online: 19 November 2002

(C) Springer-Verlag 2002 and an OGTT (75 g). On a subsequent day, a 150 min hyperinsulinaemic $\left(0.6 \mathrm{mU} \cdot \mathrm{kg}^{-1} \cdot \mathrm{min}^{-1}\right)$ euglycaemic clamp was carried out to assess insulin-stimulated glucose uptake (M-value).

Plasma samples were collected in tubes with aprotinin/ EDTA solution in an ice bath and frozen immediately and kept at $-80^{\circ} \mathrm{C}$. Total plasma ghrelin was measured with a radioimmunoassay as described previously [5]. Plasma glucose was measured immediately after sampling (Beckman Instruments, Palo Alto, Calif., USA). Serum insulin was determined by ELISA, and body composition was evaluated by dual energy X-ray absorptiometry.

Data are given as means \pm SD or geometric mean and range, as appropriate. Student's two-tailed $t$ test for unpaired data was used for comparison of data between groups. Correlations were examined using Pearson's correlation analysis. Furthermore, data were analysed by using multivariate linear regression analysis with ghrelin as the dependent variable. Due to the graphical impression of a curvilinear relation between insulin and ghrelin, an exponential model was applied. All statistical analyses were done by using SPSS for Windows version 10.0 (SPSS, Chicago), and a $p$ value of less than 0.05 was considered statistically significant.

The offspring group was insulin-resistant compared to the control group (M-value; $4.52 \pm 1.87$ vs. $6.45 \pm 2.77 \mathrm{mg} \cdot \mathrm{kg}^{-1} \cdot \mathrm{min}^{-1}$, $p<0.05)$. Fasting plasma glucose $(5.1 \pm 0.5$ vs. $4.8 \pm 0.4 \mathrm{mmol} / \mathrm{l}$, $p<0.05)$ and $120 \mathrm{~min}$ plasma glucose $(5.9 \pm 0.9$ vs. $4.6 \pm$ $1.1 \mathrm{mmol} / 1, p<0.001)$ were increased in the offspring group. However, all had a normal OGTT. Whereas fasting concentrations of serum insulin did not differ between groups [34.0 (14.0-100.5) vs $29.1(16.0-66.0) \mathrm{pmol} / \mathrm{l}, p=0.24]$, mean serum insulin concentrations [194.8 (83.9-788.4) vs 145.4 (69.4244.7) $\mathrm{pmol} / \mathrm{l}, p=0.05]$, as well as area under the curve of serum insulin during the $180 \mathrm{~min}$ OGTT (45 688 [20 333-190 995] vs 33440 [16 388-55 271] pmol.1 $\left.\mathrm{l}^{-1} \cdot 3 \mathrm{~h}^{-1}, p=0.05\right)$, were higher in the offspring group. Men and women were comparable with respect to age, BMI, and insulinaemia, but, as expected, women were characterized by an increased body fat content.

Fasting plasma ghrelin was substantially $(\sim 25 \%)$ reduced in the offspring group [138.0 (55.9-237.0) vs 183.3 (97.0-287.7) 